\title{
Cultivating High-Quality Talents by Improved Teaching Model of Morality and Law Course
}

\author{
Guang-Mei LIN ${ }^{1, a,}, K_{\text {Kun BAI }}^{2, b, ~}{ }^{,}$,Zhen KONG ${ }^{1, c,}$ Ling-HanKONG ${ }^{3}$ \\ ${ }^{1}$ Beijing Information Technology College, No. 5, Fangyuanxilu, Chaoyang District, Beijing, China \\ ${ }^{2}$ University of International Relations, No. 12, Poshangcun, Haidian District, Beijing, China \\ ${ }^{3}$ Beijing Bayi School, No. 29, Suzhoujie, Haidian District, Beijing, China \\ a'Lingm@bitc.edu.cn, ${ }^{\mathrm{b}}$ Baikun@uir.edu.cn, ${ }^{\mathrm{C}}$ Kongz@bitc.edu.cn
}

${ }^{*}$ Corresponding author

Keywords: Students; Vocational College; Politics; Teaching model; Law.

\begin{abstract}
Teaching model is one of the important ways to realize the goal of cultivating the high-quality talents. The improved teaching model research focuses on exploring the course of Morality and Law by deigning targets, paths, content, methods and evaluation ways, to enhance the efficiency and effect. The research group made a questionnaire survey in Beijing among students in 6 colleges and staff in 67 enterprises covering the fields of state-owned, private, sino-foreign joint ventures or foreign-funded companies. The group also made interview with counselors and deans. By careful analysis, the team summarized "1133" teaching model demonstrating new definition of the target, methods, and evaluation.
\end{abstract}

\section{Introduction}

Ideological and political theory coursesare the main channel of the ideological and political construction which the CPC central committee has been very concerned about. Strengthening and improving ideological and political education of the guiding ideology, basic principles, basic requirements, main ways and methods is more and more important in the $13^{\text {th }}$ Five Year Plan. A series of documents have been published for the curriculum plan and deployment under the new situation. The course should be what students really love, bringing lifelong benefit. The construction of the ideological and political theory courses should focus on how to improve the effective realization of the aims of education. Mission of vocational colleges is to train high-quality, highly skilled personnel. High quality as the core includes higher moral quality and clearer sense of law.

\section{Data Analysis}

The survey data is analyzed by SPSS software. Therefore, this suggests that further curriculum reform is very necessary. Based on the student questionnaire survey statistics and comparative analysis, the present situation is summarized as follows.40.4\% students are very satisfied with the course and $1.9 \%$ students are satisfied with it. 57.2\%students want to improve their own thoughts and are attracted to the course content; $42.8 \%$ students learn the course to cope with the examination. However, 23.1\% students think the course has little or no help. Most students hope teachers adopt the way of teaching. $15.9 \%$ students want to take a purely theoretical teaching, $37.2 \%$ want topic discussion-based teaching, $40.9 \%$ want case analysis. Pure theoretical teaching is unpopular. The effect of the video teaching method is arousing interests in learning. 40.1\%students think video effect is very good, $36.7 \%$ think it is good. The task driving method is improving the ability to learn. $71.4 \%$ students think of task driving as a method to improve the learning ability. It can be seen that $59.3 \%$ of the students like surfing the Internet to find information in class. Group discussion achieves the best learning effect.47.3\% students in class seldom listen to the lecture. Students like to participate in the practice of course activities, with $39 \%$ loving off-campus visit. 
With declining cognitive ability of vocational college students, teachers really need a thorough reform to explain the theory, to arouse the interest in study.

\section{Establishing a Scientific World View}

In view of the above problem analysis, course development is very necessary. First of all, political theory course is intended to enable the students to establish a scientific world view, by providing basic Marxist views, positions and methods of understanding social development and the laws. That may result in a love for the motherland, for the people, and for the socialism with Chinese characteristics. To achieve such a purpose, practice under the theoretical validation and reproducibility will take place, becoming the driving force and source of theoretical innovation.

\section{The Practical Education Connecting}

According to Marxist theory, qualitative change is advancing through continuous integration with practice and times. In this regard, teachers in the classroom are responsible for integrating theory with practice. On the other hand, young students connect their understanding with the reality to be, thankful to the development and changes of society. Practical education is to train students to know the community, to understand the country, by effective means of ideological and political theory courses which outline the most important items indispensable. With the deepening of China's educational reform, emphasizing the combination of theory and practice has become a consensus. Environment of the society as a whole made this kind of teaching also feasible.

\section{Broken ivory Tower}

Previously, the so-called “ivory tower” in colleges as has been broken. Teachers' engagement in practice with a strong scientific research has become a trend. Under such circumstances, the practice of political theory course can be described as a flow to reflecting the river of the society. Many institutions have added the practice of extra-curricular links outside the classroom, which benefits the political class education for guidance in practical fields under an objective condition. Carried out in practice is a major challenge. It requires the teachers to change the traditional teaching philosophy of education which simply focusing on talking about textbooks. Instead, teachers had better provide in-depth understanding of the society, and social realities of life, using theory to guide practice and testing theory with practice. In this process, students discuss with peers and the teachers who organize theoretical preparation. Inspired and guided by teachers, students become so motivated to learn, to think about social phenomena and problems by themselves.

\section{The Practice Session}

Classroom teaching can only be regarded as part of doing a good job of teaching practice, the foundation and groundwork. Success needs the following efforts: available time, appropriate topics and appropriate practice of place. The practice session makes students go outside the classroom environment in extra-curricular time to carry out, so the timing must be expedient. In general, the annual winter and summer vacations are properly engaged in activities of social practice. The college adjusts the examination procedures and time for the practice of the performance of students and the completion of the operation of the organization. The political theory course can take advantage of this opportunity to students for professional practice at the same time, but also to understand the community to complete a political theory course requirement. We must select the best practice themes and venues of practice to produce the desired effect, or even the opposite trend. We must seize this outstanding achievement in the community or a problem. It is also necessary to select several representative industries or regions as a base for the practice, which could facilitate contacts and arrangements. Students are encouraged to express their views fully during the course of social practice. 


\section{Providing Enough Training}

Training involves much more than just talking to people; it requires posing intelligent questions that inspire the students to talk about their thoughts, their work and their concerns. Teachers can use a proactive process to help them upgrade their skills, reach their own solutions and understand their own actions.

\section{Information Means}

In order to provide enough interesting training, teachers take three information means to mobilize students' learning interest. The first is the improvement on classroom learning strategy. Simplified and exquisite PPTattracts the attention of students. Students learn professional video effectively. The second is the use of computer network teaching platform which realizes online teaching, answering questions and submitting homework. The third is use of communication network, such as WeChat, QQ and Fetion, stimulating students' enthusiasm on main theory content. These means help demonstrating difficulties with vivid animation and music to facilitate students' class activities. Taking education online, instead of in a classroom is a change for many people. So teachers get to have a strategy to convert learners to online training.

\section{Strengthening Practice in Training}

Teaching in class must provide more and more practice. Through the survey, we have already found that students want the teacher to take practice teaching. Due to the limited capital, off-campus practice cannot take place too frequently. Practice teaching takes the following three ways. First is the classroom practice, using the typical case to illustrate the theory to solve a series of problems. Second is campus practice, organizing campus research, interviews, and moot court. Third is outside-school visit in patriotism bases, anti-drug bases and the courts to strengthen the book knowledge. So the task-driven teaching method increases proportion of practice inside and outside the classroom. The method has the core of "teaching, learning and doing", in order to improve students' practical application ability. That could also improve the teaching effect of teaching in the practice training bases.

\section{New teaching Model}

Existing teaching model is "113" which has 1 subject, 1 guide, and 3 practice models. Along with the rapid development of informatization, the generation born after 1995 is more interested in the information way to accept knowledge. Therefore, based on the 113 model, teachers adjust the teaching mode as "1133" to highlight 3 kinds of informationization means using three kinds of practice teaching models, closer to the vocational students' characteristics. The purpose is to improve students' practical application ability. Instead of evaluation of theoretical knowledge, examination needs further change to attract attention, to improve the process of learning behavior and application ability. And teachers need to further develop the students' participation, to arouse the enthusiasm of students, and to form a good habit. With the popularity of smart phones, we can make full use of network access to course related information, giving assignment on online platforms, stimulating interaction between teachers and students.

\section{Supporting Materials}

So as to improve classroom efficiency, teachers have to use some new and special teaching materials for students. A complete set of study guide can make the students grasp the emphases and difficulties of learning. Five modules to be a better man obeying morality and law help students understand the dos of a professional person in a series of tasks. By clarifying learning targets, students digest and absorb the teaching material content through the exercises in order to improve the effectiveness as well as quality goals. Self-discipline students are more able to cooperate with other classmates. The training make them competent and confident. 


\section{Summary}

The teachers' efforts are the vital part of improving the attraction and infectivity of college ideological and political theory courses. The courses can play an important role in the process of constructing socialist harmonious society. Therefore, we must strengthen and improve the new ways and new methods to do the college ideological and political work well. Primarily, the 1133model is offered as an alternative method of political teaching model providing a novel approach to the analysis of ideologies, through examining their internal conceptual morphology. The result is to interpret ideologies as particular combinations of meaning from an indeterminate range of meanings at the disposal of a society. Hence, ideologies are located at the meeting point between logic (internal constraints on their permutations), culture (the impact of social practices and events over time and space) and the regularities of morphological patterning that they display.

\section{Acknowledgement}

This research was financially supported by Beijing Education Science "12th five-year" Plan Project Research on Social Responsibility Cultivation Model of Vocational College Students in Beijing DFB13123, by CPC Beijing Municipal Education Committee Project Research on Teaching Model of Morality and Law in VocationalCollegesBJSZ2015ZC235hosted by Guangmei Lin, and by Beijing Information Technology College Research Subject XY-YN-14-201516.

\section{References}

[1] Wei HONG, Youth Navigation. Scientific and Technical Documentation, Beijing, 2013

[2]Michael Bungay Stanier, The Coaching Habit: Say Less, Ask More \& Change the Way You Lead Forever, Box of Crayons Press, New York, 2016

[3]Marx and Engels, Collected Works, Volume 42, People's Publishing House, Beijing, 1979 